\title{
A case report: autosomal recessive limb girdle muscular dystrophy caused by a novel mutation (c. 287A > G) in POMT2 gene of a Chinese Han patient
}

\section{Yanlu Gao}

Jilin University First Hospital

Zhixia Kang

Jilin University First Hospital

\section{Xiaojing Wei}

Jilin University First Hospital

Jing Miao

Jilin University First Hospital

Xuefan Yu ( $\nabla$ xuefan@jlu.edu.cn )

\section{Case report}

Keywords: Limb girdle muscular dystrophy POMT2 gene autosomal recessive

Posted Date: March 22nd, 2019

DOI: https://doi.org/10.21203/rs.2.483/v1

License: (1) (i) This work is licensed under a Creative Commons Attribution 4.0 International License. Read Full License 


\section{Abstract}

BACKGROUND Autosomal recessive limb girdle muscular dystrophy $2 \mathrm{~N}$ is caused by mutations in the POMT2 gene. The disease is characterized by proximal muscle weakness, with minimal progression, with cognitive impairment,a significantly elevated serum level of creatine kinase. CASE PRESENTATION A 9year-old boy presented with proximal muscle weakness since the last 4 years, with minimal progression. There was no significant family history.Medical examination showed no generalized muscle hypertrophy. Serum creatine kinase level was 52 -fold higher than the normal value. Wechsler Intelligence scale for Children (WISC, 4) suggested mild cognitive impairment (IQ =74). DNA sequence analysis identified a novel missense mutation (c. 287A > G) and a known mutation (c. 1261C > T). CONCLUSIONS This case report of autosomal recessive limb girdle muscular dystrophy $2 \mathrm{~N}$ caused by a novel compound heterozygous mutation expands the genotypic spectrum of POMT2 gene.

\section{Background}

Mutations in POMT2 are generally associated with Walker-Warburg syndrome(WWS) and Muscle-EyeBrain disease(MEB), but also can cause limb girdle muscular dystrophy (LGMD2N) [1]. The gene is located in chromosome 14q24.3 and has 21 exons. It encodes protein 0-mannosyltransferase, which exists in the the endoplasmic reticulum[2].This protein is a component of the protein 0mannosyltransferase enzyme complex which is involved in modification of the protein alphadystroglycan. LGMD $2 \mathrm{~N}$ is a kind of autosomal recessive hereditary disease. This disease characterized by progressive myasthenia, onset in infancy and slow progression of symptoms.Biancheri reported a case of mutations in POMT2 in 2007 and named for LGMD 2N for the first time. This paper reports a new mutation of POMT2 in a patient whose clinical manifestations and muscle biopsy results are consistent with LGMD 2N. The POMT2 showed c. 287A > G and c. 1261C > T, those mutated respectively from their parents. The former has not been reported in literature, which may cause the disease.

\section{Case Presentation}

The patient,now 9 years old,is a male born to non-consanguineous parents with no family history of muscular dystrophy. The pedigree of her family revealed an autosomal recessive inheritance patern(Fig.1).He met early developmental motor milestones though onset of walking occurred at 18 months. At five years of age,he suffered progressively proximal muscle weahness. And be inferior to their peers in sports, easy to fall down. His attention is not concentrated during class,so he has poor grades in his studies,and his reaction is slightly slow.He was thin,muscle weakness was detected in the biceps and triceps muscles (MRC5-/5), and quadriceps muscles (MRC 4-/5), His distal arm strength was 5.No cranial nerve dysfunction or sensory disturbance was noted. His serum level of creatine kinase was 52fold higher than the upper normal value. Wechsler Intelligence scale for Children (WISC, 4) suggested mild cognitive impairment $(\mathrm{IQ}=74)$. Echocardiography and electrocardiogram evaluations did not detect any cardiac abnormalities.Image and transverse T1-weighted muscle MR image demonstrated no obvious abnormality(Fig.2).After the patient'mother provided written consent, a skeletal muscle biopsy was taken 
from the musculus biceps, precooled with isopentane, and frozen in liquid nitrogen. Frozen sections of $8 \mu \mathrm{m}$ were prepared and histopathological examination showed increased fiber size variability with atrophic and hypertrophic fibers.Plscattered or groups of fibers undergoing necrosis or regeneration, with inflammatory cell infiltration. There was a mild increase in connective tissue(Fig.3a).succinate dehydrogenase (SDH) and cytochrome c oxidase (COX) staining showed reduced oxidative enzyme activities in some fibers(Fig.3b and c). a-dystroglycan staining showed a-dystroglycan was reduced in

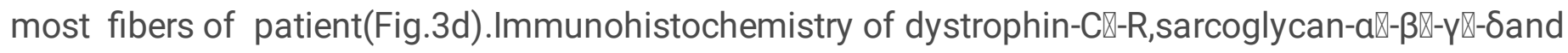
dysferlin, showed normal expression of these proteins.Next generation sequencing identified a novel missense mutation(c.278A $>G$ ) and a known mutation(c.1261C $>T$ ) of POMT2 gene(Fig.4). Genetic testing revealed that these mutations had been passed to the patient from his parents. He was put on prednisone therapy.One month later he clinical picture was unchanged, whereas CK levels were reduced.

\section{Discussion And Conclusions}

LGMD $2 \mathrm{~N}$ is an autosomal recessive inheritance pattern caused by mutations in POMT2.At the same time POMT2 gene mutation can also lead to congenital muscular dystrophy and with severe muscle-eyebrain damage Walker-warburg syndrome. [3,4,5].POMT2 gene encodes a 750-amino acid protein that is an integral membrane protein of the endoplasmic reticulum[2]The patient experienced mild proximal muscle weakness with cognitive impairment, other symptoms include borderline low left ventricular ejection fraction and mild restrictive lung disease[6]. The patient experienced proximal muscle weakness from five years of age with minimal progression, with cognitive impairment,a significantly elevated serum level of creatine kinase, muscle MR image demonstrated no obvious abnormality.Muscular dystrophy with mild inflammatory changes and a-dystroglycan was reduced in muscle biopsy. This is consistent with LGMD $2 \mathrm{~N}$ patients. No pathogenic variants were identified in DMD $\mathrm{FKRP} \square \mathrm{POMT10}$ POMGNT1.POMT2 gene analysis revealed two complex heterozygosity mutations, one of which was c.1261C > T (p.Arg421Trp), and the pathogenicity of the mutation was reported in literature囚associated with limb girdle muscular dystrophy with very mild learning disability; another mutation was c. 287A > G (p.Tyr96Cys), which is not present in the dbSNP,1000Genomes database; three different softwares analyse are used to predict that the mutation of c. 287A > G:deleterious(SIFT),probablydamaging(Polyphen2),disease_causing (MutationTaster). The complex heterozygosity in patients with POMT2 gene came from his parents. which was consistent with the autosomal recessive genetic pattern. We speculate that the above variation is the pathogenicity variation leading to the pathogenesis of the patients.

In conclusion,LGMD $2 \mathrm{~N}$ is an autosomal recessive hereditary disease, its cognitive impairment is different from other LGMD. Because of the minimal progression of proximal muscle weakness, muscle biopsy is of significance for diagnosis[7]. The final diagnosis depends on genetic testing.

\section{Abbreviations}

LGMD: limb-girdle muscular dystrophy 
MRI: magentic resonance imaging

HE: hematoxylin-eosin

SDH: succinate dehydrogenase

COX: cytochrome c oxidase

\section{Declarations}

Ethics approval and consent to participate

Not applicable.

Consent to publish

Written informed consent for publication of this Case Report was obtained from the patient and his mother. A copy of each written consent form is available for review to the Editor of this journal.

Availability of data and materials

All data generated or analysed during this study are included in this published article [and its supplementary information files].

Competing interests

The authors declare that they have no competing interests.

Funding

Not applicable.

Authors' contributions

YG drafted the manuscript and figures; XW designed and analyzed the study; ZK analyzed and interpreted histological data; $X Y$ and JM revised the manuscript and gave the final approval of the version to be published. All authors read and approved the contents of the case report.

Acknowledgements

The authors thank Medjaden Bioscience Limited for proofreading the manuscript.

Authors' information

All of authors are from the Department of Neurology and the Neuroscience Center of the First Hospital of Jilin University. 


\section{References}

[1] Brun BN,Willer T,Darbro BW,Gonorazky HD,Naumenko S,Dowling JJ,et al.Uniparental disomy unveils a novel recessive mutation in Neuromuscular Disorders 000 (2018) 1-5.

[2] T. Willer, W. Amselgruber, R. Deutzmann, S. Strahl, Characteriza-tion of POMT2,a novel member of the PMT protein 0-mannosyl-transferase family specifically localized to the acrosome of mammalian spermatids, Glycobiology 12 (2002) 771-783.

[3] Godfrey C, Clement E, Mein R, Brockington M, Smith J, Talim B, et al. Refining genotype phenotype correlations in muscular dystrophies with defective glycosylation of dystroglycan. Brain 2007;130(Pt 10):2725-35.

[4] van Reeuwijk J, Janssen M, van den Elzen C, Beltran-Valero de Bern- abe D, Sabatelli P, Merlini L, et al. POMT2 mutations cause alphadystroglycan hypoglycosylation and Walker-Warburg syndrome. J Med Genet 2005;42:907-12.

[5] Mercuri E,D’Amico A,Tessa A,Berardinelli A,Pane M,Messina S,van Reeuwijk J,Bertini E,Muntoni F,Santorelli FM.POMT2 mutation in a patient with 'MEB-like'phenotype.Neuromuscul Disord 2006;16:4468.

[6] Ostergaard ST, Johnson K, Stojkovic T, Krag T, De Ridder W, De Jonghe P, et al. Limb girdle muscular dystrophy due to mutations in POMT2. J Neurol Neurosurg Psychiatry 2017. doi:10.1136/ jnnp-2017317018.

[7] Biancheri R, Falace A, Tessa A, Pedemonte M, Scapolan S, Cassan- drini D, et al. POMT2 gene mutation in limb-girdle muscular dys- trophy with inflammatory changes. Biochem Biophys Res Commun 2007;363:1033-7.

\section{Figures}




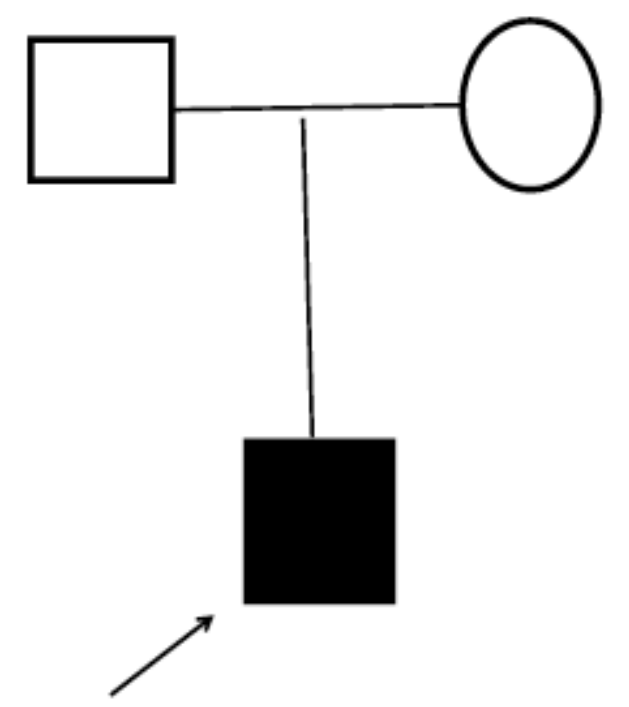

\section{Figure 1}

Pedigree of the patient's family. The affected members are indicated with black. Squares and circles represent males and females, respectively. Arrow indicates the case of the report. 

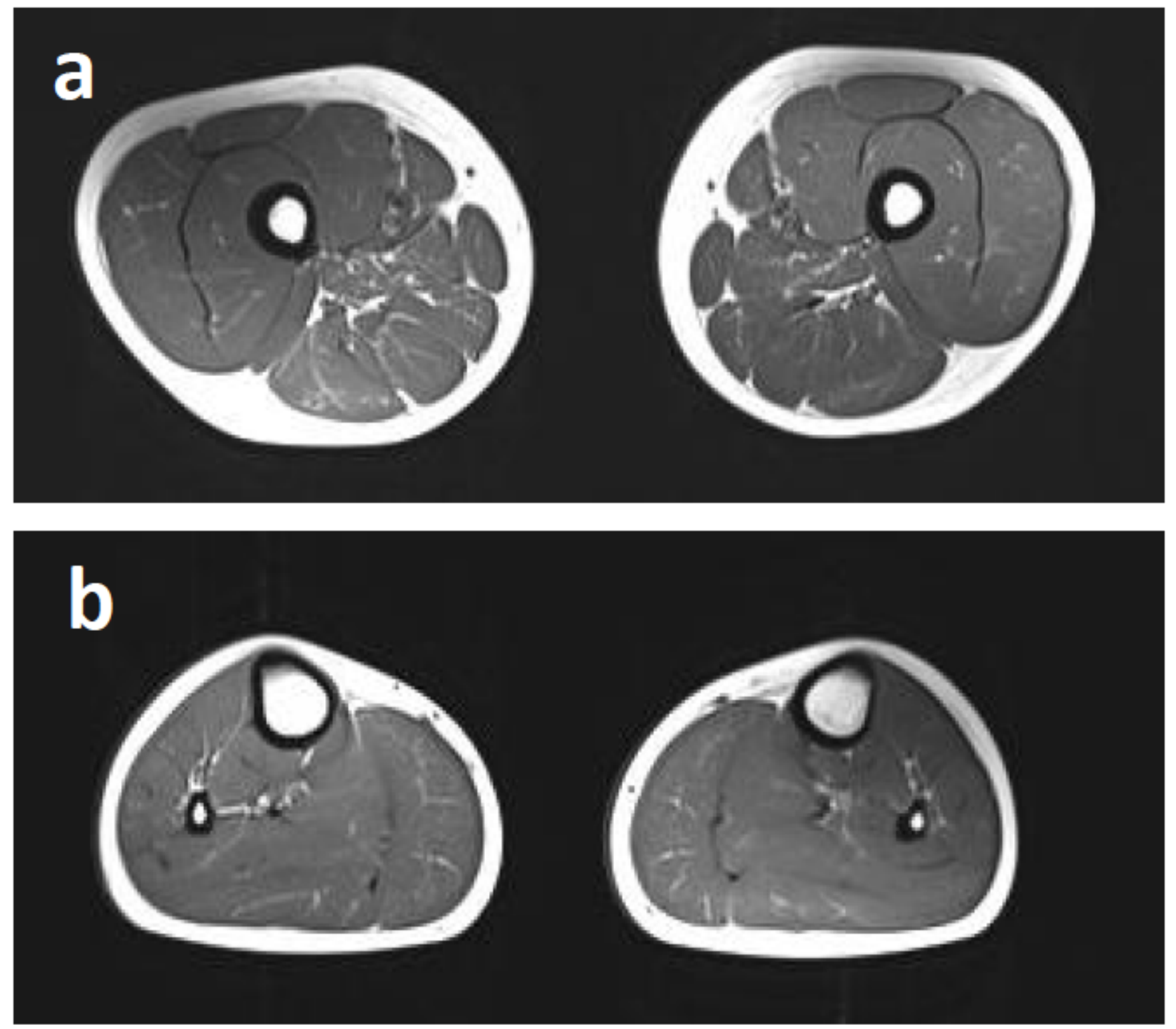

Figure 2

Image and transverse T1-weighted muscle MR image from the patient. MR images demonstrated no obvious abnormality.

原

\section{Figure 3}

Histopathological examination of the skeletal muscles. a HE staining showed muscle fibers of variable sizes,plscattered or groups of fibers undegoing necrosis of regeneration(black arrow), b SDH and (c) COX staining showed reduced oxidative enzyme activities in some fibers(red arrow), d a-dystroglycan staining showed a-dystroglycan was reduced in most fibers of patient. 

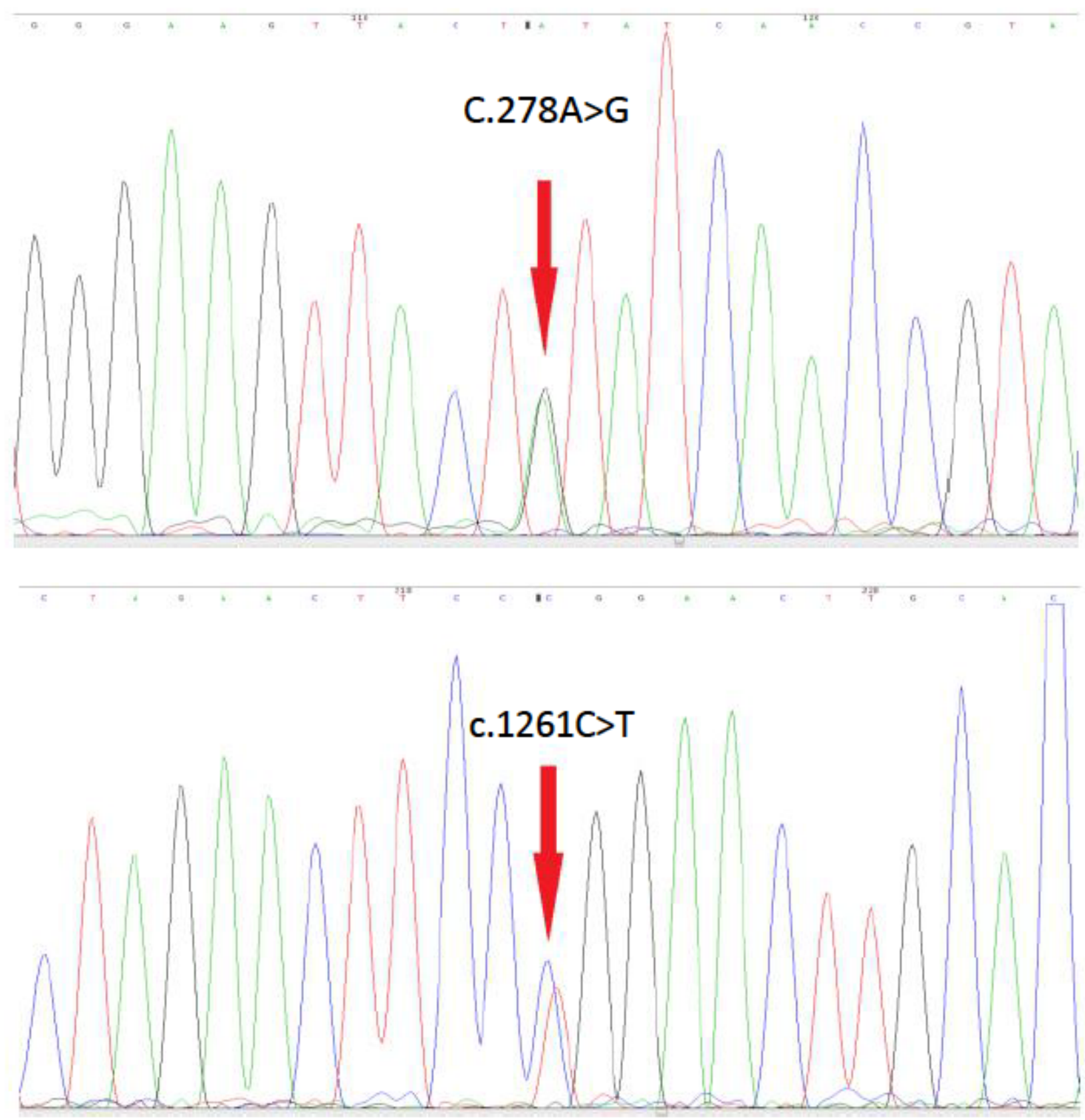

Figure 4

DNA sequencing analysis showed a novel missense mutation(c. $278 \mathrm{~A}>\mathrm{G})$ and a known nutation(c.1261C>T) of POMT2 gene. (red arrows)

\section{Supplementary Files}

This is a list of supplementary files associated with this preprint. Click to download.

- supplement1.doc 